\title{
Ensino superior de tecnologia na modalidade a distância: uma experiência no Instituto Federal de Santa Catarina (IF-SC) através do curso de Gestão Pública
}

\author{
Plínio Cornélio Filho, IF-SC, plinio@ifsc.edu.br \\ Júlio César da Costa Ribas, UFSC (PGEGC) / IF-SC, julio@ifsc.edu.br
}

\begin{abstract}
Resumo: Este artigo contextualiza a educação a distância e relata a trajetória do Instituto Federal de Educação de Santa Catarina - IF-SC, na implantação da modalidade de EaD através do modelo de gestão do Curso Superior de Tecnologia em Gestão Pública, implementado através do Programa Universidade Aberta do Brasil na unidade de ensino de Florianópolis/SC. Detalha a dinâmica de funcionamento administrativo e pedagógico, de forma a facilitar, com base na experiência prática, o caminho daqueles que em breve se tornarão co-participantes de trocas de experiências, gerando um ciclo, de maneira a contribuir para um redesenho do próprio modelo adotado pelo IF-SC.
\end{abstract}

Palavras-chave: educação a distância, gestão, universidade aberta

\section{Higher education in technology in distance mode: an experience at Santa Catarina Federal Institute (IF-SC) through the Public Management course}

Abstract: This article analyzes distance education and describes the trajectory of Santa Catarina Federal Institute - IF-SC, during the implementation of distance education mode, by means of the management model of the Course of Technology in Public Management, implemented through the program Brazil Open University at the campus Florianópolis/SC. The article details the dynamics of administration and teaching, in order to facilitate, based on practical experience, the way of those who will soon become co-participants in the exchange of experiences, generating a cycle so as to contribute for a redesign of the model adopted by IF-SC.

Keywords: distance learning, management, open university

\section{INTRODUÇÃO}

Estudos realizados em universidades brasileiras e americanas indicam que programas semipresenciais tendem a oferecer cursos com qualidade igual ou superior aos cursos presenciais. Desta forma, há uma tendência no ensino superior à adoção de sistemas mistos, que contemplam cursos com atividades presenciais e a distância. Castro (2002) e Verduin (1991) indicam que o modelo integrado apresenta uma boa relação custo/benefício para as Instituições de Ensino Superior (IES). Grande parte das IES brasileiras tem utilizado esse modelo, pois o mesmo não provoca desgaste entre os ensinos presencial e a distância.

Maia (2003), em estudo realizado pela Escola de Administração de Empresas de São Paulo, da Fundação Getúlio Vargas, investigou 47 IES. A maior parte dos cursos a distância oferecidos por elas eram para formação de professores, e os mais frequentes eram os de graduação, representando 39\% da amostra. No mesmo estudo, os cursos de graduação representaram a maior carga horária (até 3.264 horas-aula), e nenhum deles era oferecido totalmente a distância. Isto é, em 70\% dos casos, o modelo era semipresencial e apenas os cursos de aperfeiçoamento, especialização e extensão eram totalmente a distância. Em termos de recursos tecnológicos para interação aluno/professor/tutor, 98\% dos cursos analisados utilizavam a internet e, além dela, 
recursos computacionais como CD-ROM para disponibilização de conteúdo, a videoconferência como ferramenta de comunicação síncrona entre professor e aluno fisicamente distantes e a teleconferência, que se diferencia da videoconferência por não permitir interação síncrona entre os participantes. Constatou-se também que, em 57\% dos cursos a distância, outras formas de avaliação foram utilizadas, como a participação em fóruns, chats e outras atividades on-line. Porém, segundo Pimentel (2006), o formato presencial de avaliação de aprendizagem preponderou sobre o formato à distância (77\% contra 23\%).

Um grande número de pesquisas, tais como as dos autores citados, têm revelado o que o estímulo em EaD tem proporcionado, fomentando grande capacidade de produção de conhecimento e desenvolvimento de soluções próprias em EaD pelas instituições brasileiras de ensino. Outro fator contribuidor para isso é a evolução das tecnologias de informação e comunicação, cada vez mais amigáveis, passíveis de compreensão autônoma, potencializadoras de idéias, aliciadoras de um número maior de docentes no seu uso e, consequentemente, facilitadoras no processo de ensino-aprendizagem. O estímulo à EaD, aliado à evolução das TICs, tem promovido mudanças profundas no panorama do ensino e da aprendizagem e proporcionado desenvolvimento de excelentes trabalhos nacionais. Alguns projetos de plataforma para gerenciamento de cursos a distância, por exemplo, foram desenvolvidos no Brasil: o Ambiente AVA - Ambiente Virtual de Aprendizagem, desenvolvido pela UNISINOS; o software AulaNet, desenvolvido pela PUC-RJ; o ambiente TelEduc, desenvolvido pela UNICAMP; o Projeto Virtus, desenvolvido pela UFPE, e o sistema VIAS-K, desenvolvido pela UFSC.

De acordo com Schneider (1999),

As universidades europeias a distância têm incorporado em seu desenvolvimento histórico as novas tecnologias de informática e de telecomunicação. Um exemplo disso é o desenvolvimento da Universidade a Distância de Hagen, que iniciou seu programa com material escrito em 1975. Hoje, oferece material didático em áudio e videocassetes, videotexto interativo e videoconferências. Tendências similares são observadas nas Universidades Abertas da Inglaterra, Holanda e Espanha. Hoje mais de 80 países, nos cinco continentes, adotam a EaD em todos os níveis de ensino, em programas formais e não formais, atendendo a milhões de estudantes.

Desta forma, a escolha adequada dos recursos tecnológicos assim como o planejamento para a implantação dos cursos passaram a ser fundamentais para o sucesso do empreendimento.

É facilmente perceptível o grande esforço das instituições de ensino em se adequarem às políticas e diretrizes governamentais atuais de apoio à expansão do ensino a distância, de modo a poderem participar ativamente do desafio em democratizar e simplificar o acesso ao conhecimento, exercendo assim justiça social.

O presente artigo apresenta, através de um estudo de caso, algumas estratégias administrativas e pedagógicas, diretamente relacionadas a planejamento e operação, implantadas na criação e gestão do Curso Superior de Tecnologia em Gestão Pública (CSTGP) do Instituto Federal de Santa Catarina (IF-SC), através do Programa Universidade Aberta do Brasil. Tem também como objetivo, facilitar o caminho daqueles que em breve se tornarão co-participantes na propagação da modalidade EaD. 


\section{AS UNIVERSIDADES ABERTAS}

Segundo a classificação de Moore \& Kearsley (2008), a evolução da EaD é estratificada no tempo através de três gerações, sendo que o marco da mudança da primeira para a segunda geração, em 1970, foi o surgimento das primeiras universidades abertas. A terceira geração de EaD tem seu início em 1990, com o uso de redes de conferência por computador e estações de trabalho multimídia, consequência da evolução das TICs.

Conhecidas também como Open Universities, as universidades abertas são um dos modelos de EaD para o ensino superior. O termo "aberta”, segundo Maia e Mattar (2007), tem sentido bastante amplo, envolvendo a abertura a pessoas, lugares, tempo, métodos e conceitos. Normalmente são consideradas como universidade abertas aquelas que atendem mais de 100 mil alunos. Genericamente, elas caracterizam-se por proporcionarem as seguintes condições: são de escopo nacional; apoiam-se em economia de escala, com grande número de alunos matriculados; não exigem educação prévia; os cursos ou estudos podem iniciar a qualquer momento, por quem quiser e em qualquer lugar à escolha do aluno; existe uma equipe desenvolvedora dos materiais dos cursos e outra de tutoria.

A exemplo do cenário mundial, o Brasil, através do Ministério da Educação e de sua Secretaria de Educação a Distância, buscando incentivar e coordenar projetos para estruturar a EaD nacional, criou o Sistema Universidade Aberta do Brasil - UAB.

Contando com a parceria das instituições de ensino credenciadas e autorizadas pelo MEC, o Programa UAB objetiva, mediante ensino superior público, formar administradores públicos e professores para a educação básica, e também cursos para desenvolvimento econômico regional. Os níveis educacionais abrangidos pelo programa são os de educação fundamental de jovens e adultos, educação profissional técnica, ensino médio, graduação e pós-graduação. Atualmente a UAB está em sua terceira etapa. Na primeira etapa (UAB1), as Instituições Federais de Ensino Superior (IFES) puderam ofertar cursos de graduação, sequenciais, lato sensu e stricto sensu, gerando 35.000 vagas, objetivando a formação de professores. Com as etapas UAB2 e UAB3, os mesmos cursos puderam ser ofertados também pelas instituições de ensino estaduais e municipais, totalizando 180.000 vagas. Para todas as etapas, foram criados Polos de Apoio Presencial (PAP) destinados a oferecer recursos humanos, tecnológicos e espaço físico aos alunos da região, de maneira a garantir o processo de ensino e aprendizagem. Ao todo, foram 562 polos; 8,2\% instalados na região centro-oeste brasileira, 27,7\% no sudeste, 15,2\% no norte, 31,6\% no nordeste e 17,3 \% no sul. A projeção para 2010 são novos editais, objetivando 1.000 polos e 300.000 novas vagas no sistema educacional superior. Até 2013, projeta-se que o sistema ampliará sua rede de cooperação para alcançar todas as instituições públicas de ensino superior brasileiras e atender a 800 mil alunos/ano.

Especificamente em Santa Catarina, a UAB está presente por meio das parcerias realizadas com o Instituto Federal de Educação, Ciência e Tecnologia de Santa Catarina (IF-SC), a Universidade Federal de Santa Catarina (UFSC) e a Universidade para o Desenvolvimento do Estado de Santa Catarina (UDESC).

\section{O IF-SC E O SEU CONTEXTO EM EAD}

Desde 2000, o IF-SC vem ofertando cursos na modalidade à distância. Dois exemplos marcantes são o Curso Técnico Semipresencial de Eletrotécnica para funcionários da ELETROSUL, oferecido pelo Campus de Florianópolis e os cursos de Formação Inicial e Continuada ofertados pelo Campus de São José, para aperfeiçoamento profissional de 
trabalhadores, sem formação convencional, atuantes na área de refrigeração e condicionamento de ar.

Em função da grande ênfase do ensino a distância nos cursos de graduação, o IF-SC aceitou mais um desafio na modalidade $\mathrm{EaD}$ ao investir na proposta do Ministério da Educação através do programa UAB. Assim, em 2006, empreendendo sua tradição e talento centenário no ensino, o IF-SC, através do Edital de número 1, de 16 de dezembro de 2005, implantou o Curso Superior de Tecnologia em Gestão Pública (CSTGP) com a seguinte proposta:

- Formar profissionais com visão no desenvolvimento de processos de gestão e de novas tecnologias, utilizando ferramentas de gestão, controle e avaliação;

- Atualizar os conhecimentos técnicos, favorecendo a inserção do aluno/servidor no novo contexto profissional e de gestão; e

- Possibilitar aos profissionais adquirir visão sistêmica de processos, através de soluções alternativas melhores no contexto de trabalho e de atendimento.

O modelo idealizado para esse projeto segue nas próximas seções.

\section{A IMPLANTAÇÃO DA UAB NO IF-SC ATRAVÉS DO CSTGP}

Pelas exigências do Edital 1-MEC/SEED/UAB, surgiu um novo conjunto de referenciais estruturantes e organizacionais que precisavam ser atendidos pelo IF-SC para viabilizar a oferta em EaD. Do ponto de vista pedagógico e de gestão, várias transformações ainda vêm ocorrendo, sendo elas:

- Desenvolvimento de pesquisa e implementação de trabalhos de extensão, conhecidos e respeitados em todo o território catarinense;

- Desenvolvimento de maturidade didático-pedagógica, ampliando as áreas de atuação, a oferta de vagas e modificando a natureza dos cursos;

- Descentralização, renovação e inovação administrativa, democratizando o sistema administrativo e o relacionamento entre departamentos e pessoas;

Criar mecanismos capazes de propiciar o planejamento, a organização, a capacidade de direção e de controle, segundo Oliveira (2007), é elemento basilar para que as organizações atinjam seus objetivos. Desenvolver programas e projetos, contemplando o resultado do planejamento elaborado pelas organizações, é, atualmente, uma atividade quase que trivial, embora desenvolvida por muitas organizações com deficiências, principalmente, com relação ao desdobramento dos objetivos do planejamento em questão.

Tendo em vista uma demanda geral de formação de quadros na área de gestão, o CSTGP foi selecionado para ser o marco de implantação de oferta de vagas regulares no ensino superior, na modalidade à distância.

Nesse contexto, fixaram-se as seguintes questões estratégicas: implantação dos Polos de Apoio Presencial nos municípios de oferta do curso; implementação da estrutura no IF-SC; capacitação dos envolvidos; produção de material didático; definição de mecanismos de gestão das TICs; implantação e gestão do curso propriamente dito.

Conforme Colombo (2004), o planejamento consiste na identificação, na análise e na estruturação dos propósitos da instituição rumo ao que se pretende alcançar, levando em consideração suas políticas e recursos disponíveis. No nível tático, o planejamento é expresso através dos planos de ação, nos quais são considerados os meios para a concretização dos objetivos. Oliveira (2007) corrobora, afirmando que planejamento é um processo que permite estabelecer a direção a ser seguida por meio de 
planos de ação, visando atingir os objetivos e as metas, a partir das questões estratégicas estabelecidas, procurando, assim, uma maior e melhor interação com a realidade. O planejamento, portanto, objetiva manter a sintonia com todas as etapas da implantação do Projeto UAB.

A coordenação geral do programa Universidade Aberta do Brasil no IF-SC e a coordenação de curso, balizadas pelas orientações de Oliveira e Colombo, criaram equipes multidisciplinares e planejaram a implantação do curso através das seis etapas que seguem:

1) Implementação dos Polos: prevendo a implementação, nos polos, de Equipe Multidisciplinar do Polo de Apoio - EMPA;

2) Implementação da Estrutura no IF-SC: concomitante à etapa 1 em termos de desenvolvimento, requerendo para sua operacionalização a implantação das Equipes Multidisciplinares EMEX e EMAG e a implantação da infraestrutura física de apoio à execução do projeto;

3) Capacitação em EaD: baseada em um cronograma de capacitação próprio;

4) Produção de Material Didático: prevendo a elaboração do material, revisão, editoração/diagramação, reprodução, distribuição, emissão de certificados;

5) Gestão das Tecnologias de Informação e Comunicação: prevendo os mecanismos de gestão da infraestrutura para execução do CSTGP;

6) Implantação e Desenvolvimento do CSTGP propriamente dito.

No ano de 2007, ingressaram 300 alunos oriundos dos estados de SP, PR e RS, como parte integrante do projeto de implantação. No ano de 2008, foram 200 ingressos; em 2009, mais 150 alunos; no ano de 2010, ingressarão mais 200 alunos. A colação de grau da primeira turma ocorreu em 21de novembro de 2009.

Com o aumento da demanda, fortalecimento da modalidade EaD e know-how adquirido desde 2006, o IF-SC, a partir deste ano de 2010, aumenta sua carteira de ofertas com três cursos de especialização, atendendo cerca de 2.360 alunos, em quatro estados (RS, SC, PR e SP), tornado-se assim um importante agente regional, disseminador do conhecimento nessa modalidade.

\section{DINÂMICA DE FUNCIONAMENTO DO CSTGP NO IF-SC}

\subsection{A oferta e a dinâmica de relacionamento}

O curso é oportunizado através de vestibular (50 vagas por polo), sendo exigida comprovação de conclusão do ensino médio. Ao aluno concluinte é garantido um diploma, equivalente ao dos cursos de graduação presenciais, emitido pelo IF-SC (decreto presidencial $\mathrm{n}^{0} 5.622$ de 20 de dezembro de 2005).

A Sede Florianópolis possui uma infraestrutura gerida por quatro coordenações: coordenação UAB, coordenação de curso, coordenação de produção de materiais e coordenação de tutoria. Nesta mesma sede é que todas as etapas anteriores à oferta da Unidade Curricular (UC), também conhecida como disciplina, acontecem. Através das coordenações: professores, tutores, coordenadores são selecionados; todos os materiais necessários para oferta das unidades curriculares (UCs) são planejados, produzidos e disponibilizados; normas, regimentos, calendários e manuais são criados e atualizados; todo o trâmite de secretaria acadêmica é conduzido.

No Polo, existe uma infraestrutura que comporta atividades acadêmicas de 50 alunos, orientados por dois tutores presenciais (tp) sendo que cada um atende 25 alunos e todos ficam sob a gestão atenta do coordenador de polo. A figura 1 ilustra as explicações: 


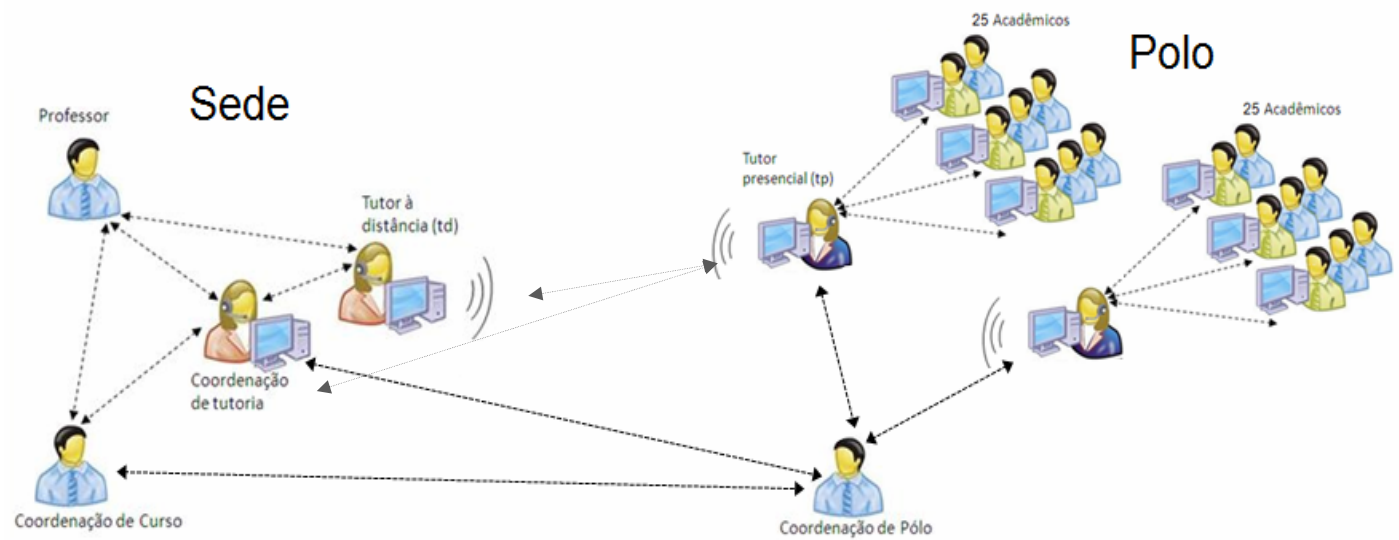

Figura 1 - Dinâmica de relacionamentos no CSTGP oferecido pelo IF-SC.

Na sede, existem tutores a distância (td), um para cada polo, liderados pela coordenação de tutoria. No CSTGP tanto tutores presenciais quanto os a distância não são conteudistas e têm como atribuições: orientar o aluno; auxiliá-lo no uso dos materiais, recursos tecnológicos e ambientes virtuais; esclarecer quanto ao funcionamento do curso e às regras do sistema de avaliação; auxiliar o professor, isto é, mediar a relação entre professores e alunos.

Tanto os tutores a distância quanto os presenciais se relacionam e orientam intensamente pelo ambiente virtual, pois em tal plataforma são registradas todas as ações, dia a dia, que acontecerão na UC. Os tutores a distância contam com outro documento vital desenvolvido pela equipe - o Plano Instrucional (PI), elaborado pelo professor durante a etapa de planejamento da UC. Nele consta como tudo que o professor planejou acontecerá (conteúdo das aulas, divisão de equipes, quantidade de tarefas, exercícios, provas, datas, regras de avaliações).

O professor é convocado para iniciar seu trabalho de planejamento da sua UC 19 semanas antes da oferta propriamente dita. Neste período ele é assessorado pela equipe de produção de materiais e pela coordenação de curso para construir seu Plano Instrucional. Quando do início de suas aulas de fato, o professor possui contato direto com os alunos, através das videoconferências, dos fóruns na plataforma moodle e das aulas presenciais (ao menos uma), quando se desloca para um dos polos e, de lá, realiza a videoconferência - momento esse muito elogiado pelos próprios alunos. A coordenação de curso subsidia, administrativa e pedagogicamente, a todos, de maneira a solucionar problemas pontuais, além de avaliar continuamente o processo de ensino e aprendizagem.

Prezando por uma comunicação eficiente, as formas de interação entre sede e polo se resumem em: videoconferência, atividades intensas através da plataforma Moodle, encontros frequentes entre gestores através do software Skype, mensagens e troca constante de documentos eletrônicos por $\boldsymbol{e}$-mail, registros de contatos entre tutores através do Sistema de Acompanhamento aos Estudantes à Distância - SAED, além de contatos e providências emergenciais realizados através do telefone.

\subsection{Estruturação e Dinâmica do Curso}

O CSTGP integraliza suas 1.680 horas em dois anos. Suas 28 Unidades Curriculares UCs, cada uma com 60 horas, que são organizadas em quatro módulos que exploram os seguintes temas, considerados fundamentais para o desenvolvimento de competências ao Gestor Público: Módulo 1 - com 480 horas, distribuídas em 8 UCs, explorando os 
Fundamentos e Ambientação em EaD e Administração Pública; Módulo 2 - com 360 horas, distribuídas em 6 UCs, abordando Legislação e Políticas; Módulo 3 - com 480 horas, distribuídas em 8 UCs, explorando Planejamento e Gestão; Módulo 4 - com 360 horas, distribuídas em 6 UCs, abordando os temas Avaliação e Conhecimento.

A Figura 2, a seguir, sintetiza a explicação:

\begin{tabular}{|c|c|c|c|}
\hline $\begin{array}{l}\text { Módulo1 } \\
480 \mathrm{~h}\end{array}$ & $\begin{array}{c}\text { Módulo } 2 \\
360 \mathrm{~h}\end{array}$ & $\begin{array}{c}\text { Módulo } 3 \\
480 \mathrm{~h}\end{array}$ & $\begin{array}{c}\text { Módulo } 4 \\
360 \mathrm{~h}\end{array}$ \\
\hline $\begin{array}{l}\text { - AVEA-Ambiente } \\
\text { Virtual de Ensino e } \\
\text { Aprendizagem } \\
\text { - Introdução a EaD } \\
\text { - Informática } \\
\text { Aplicada } \\
\text { - Comunicação } \\
\text { - Projeto e Pesquisa } \\
\text { - Modelos de Gestão } \\
\text { - Estado e Sociedade } \\
\text { - Matemática } \\
\text { Aplicada }\end{array}$ & $\begin{array}{l}\text { - Ética na Gestão } \\
\text { Pública } \\
\text { - Cenários } \\
\text { Econômicos } \\
\text { - Sistemas de } \\
\text { Politicas Públicas } \\
\text { - Legislação Aplicada } \\
\text { - Auditoria Pública } \\
\text { - Desenvolvimento } \\
\text { Ambiental } \\
\text { Sustentável }\end{array}$ & $\begin{array}{l}\text { - Planejamento } \\
\text { - Marketing } \\
\text { - Materiaise } \\
\text { Logistica } \\
\text { - Orçamento Público } \\
\text { - Contabilidade } \\
\text { Pública } \\
\text { - Finanças Públicas } \\
\text { - Gestäo de Pessoas } \\
\text { - Comportamento } \\
\text { Humano no } \\
\text { Trabalho }\end{array}$ & $\begin{array}{l}\text { - Processo Decisório } \\
\text { - Tecnologia da } \\
\text { Informação } \\
\text { - Aprendizageme } \\
\text { Inovação } \\
\text { Tecnológica } \\
\text { - Concepçãoe } \\
\text { Gestão de Projetos } \\
\text { - Gestão do } \\
\text { Conhecimento } \\
\text { - Novos Paradigmas } \\
\text { na Gestão Pública }\end{array}$ \\
\hline
\end{tabular}

Figura 2 - Módulos e respectivas Unidades Curriculares do Curso Superior de Tecnologia em Gestão Pública oferecido pelo IF-SC.

A cada seis semanas, dois professores ministram e avaliam os conteúdos de suas UCs. Desta forma, o CSTGP é concluído em 84 semanas. A Figura 3 ilustra o exposto e é utilizada para facilitar as demais explicações que seguem.

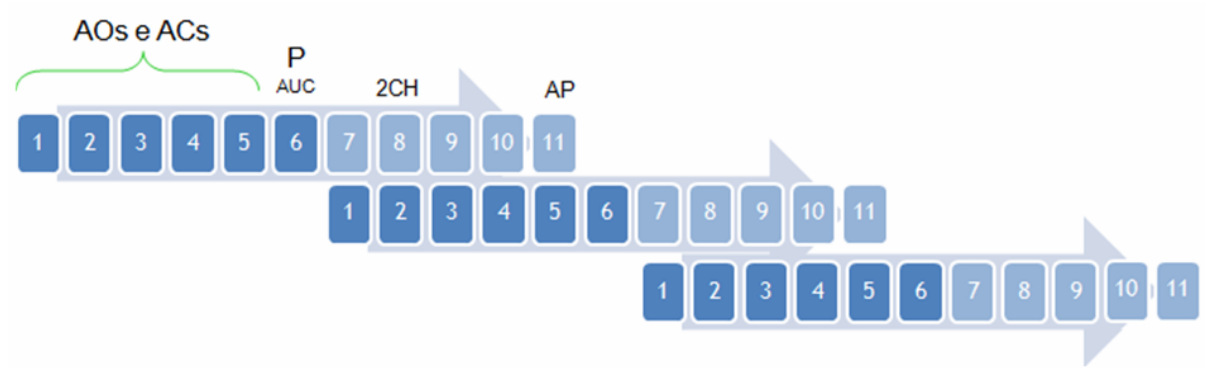

Figura 3 - Dinâmica de oferta das UCs do CSTGP oferecido pelo IF-SC

As aulas são ministradas no período noturno, uma vez por semana, através de seis interações do tipo síncrono (videoconferência). São cinco interações (uma a cada semana) utilizadas para exposição de conteúdo e mais uma (a última, na sexta semana) para realização da Prova Presencial (P) e Avaliação da Unidade Curricular (AUC), quando os alunos avaliam seu próprio desempenho, assim como a UC. Uma frequência mínima nas interações síncronas (4 das 6 existentes) é exigida e controlada. $\mathrm{Na} 8^{\mathrm{a}}$ semana, é reservado um dia para realização da segunda chamada aos casos de ausência na prova (P) amparados por lei. E na $11^{\text {a }}$ semana, é aplicada outra prova, denominada de Avaliação de Proficiência (AP), para todos os alunos que possuam frequência suficiente e não tenham obtido o rendimento mínimo exigido para a aprovação durante as seis semanas. Convém salientar que tanto na $8^{\mathrm{a}}$ quanto na $11^{\mathrm{a}}$ semana, os alunos já estão envolvidos com outras duas novas UCs, o que lhes exige empenho extra.

\subsection{Sistema de Avaliação do CSTGP}

O IF-SC adota avaliação por competências e utiliza conceitos que representam qualitativamente as competências adquiridas. São quatro os conceitos utilizados, sendo 
três de aprovação e um de reprovação: E (excelente), P(proficiente), S (suficiente) e I (insuficiente). Tal sistema de avaliação não se apoia apenas na prova (P), sua segunda chamada (2CH) e na avaliação de proficiência (AP). Além delas, as demais atividades que o compõe, e ocorrem nas seis semanas, são:

Atividades Obrigatórias (AO): são exatamente três, de cunho teórico e/ou prático e exigem acompanhamento detalhado pelos tutores. São conceituadas individualmente e isentas de recuperação pontual. Seu grau de importância é inferior ao da prova (P), mas exige-se do aluno conceito mínimo "S" em duas delas.

Atividades Complementares (AC): representam o esforço extra realizado pelo aluno no sentido de aprofundar seu conhecimento, grau de comprometimento e interesse pela UC. Servem de apoio ao professor na decisão do conceito final de aprovação do aluno na UC; isto é, o conceito final de aprovação ( $\mathrm{S}$ ou $\mathrm{P}$ ) do aluno poderá ser elevado segundo parecer do professor. Fica a critério de o professor utilizar ou não tais atividades, sendo que sua quantidade máxima deve ser três. Podem ser individuais ou em equipe e são isentas de recuperação pontual,

Atividades de Enriquecimento (AE): o professor também pode utilizar atividades de enriquecimento curricular tais como: leitura de papers, artigos, resenhas, resumos, revistas, vídeos, listas de exercícios com respostas, apresentações em MS Power Point, análise de planilhas e tabelas, etc. Tais atividades servem como estratégia de fixação ou enriquecimento de conteúdo (A unidade curricular de matemática é um exemplo clássico que utiliza $\mathrm{AE}$ ). Por não possuírem caráter avaliativo e preponderarem contextos profundos de conteúdo, são geridas exclusivamente pelo professor, com o propósito de despertar ou atender maiores interesses dos alunos pela UC.

O Conceito Final da Unidade Curricular (CFUC) é composto por: conceito final das atividades obrigatórias (AOF) e conceito da Prova Presencial (P) ou Segunda Chamada (2CH), devendo o aluno obter rendimento mínimo "S" em ambos para ser considerado aprovado na UC. Caso o aluno obtenha conceito I nas atividades obrigatórias (AOF) ou na prova (P), necessariamente deverá realizar a avaliação de proficiência (AP) para comprovar domínio de conteúdo que represente o resgate eficiente das competências anteriormente desempenhadas abaixo do mínimo exigido. Além de rendimento mínimo "S" na prova $(\mathrm{P})$ e nas atividades obrigatórias (AOF), a outra condição necessária para aprovação, conforme mencionado no item 5.2, é a frequência acadêmica, compreendida inclusive pelos alunos como diferencial do curso e fator decisivo na apreensão e troca de conhecimentos discenteldocente. A figura 4 resume o exposto:

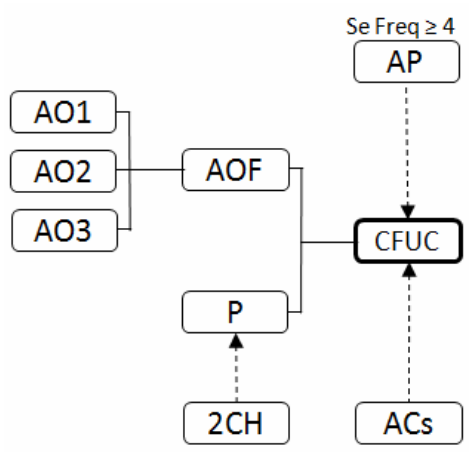

Figura 4 - Dinâmica do Sistema de Avaliação utilizado nas UCs do CSTGP/IF-SC. 
O Modelo apresentado é avaliado como bem sucedido em função da realidade em EaD que o IF-SC vivencia. Alguns pontos que comprovam o fato são: baixo índice de evasão (10\%); baixa repetência (24\%); satisfação acadêmica pela qualidade do curso; perspectiva positiva de efetiva qualificação e profissionalização na área de Gestão Pública, com contribuição para o desenvolvimento econômico regional.

No entanto, em função da projeção de crescimento da oferta na modalidade em questão, sugerem-se alguns esforços fundamentais para que se mantenham os referidos índices. São eles: melhorias no AVEA Moodle através de um suporte de informática dedicado à realidade que o curso impõe, além de sua adaptação ao sistema de avaliação por competências, no qual notas numéricas comprometem os resultados; redução da rotatividade de tutores; maior envolvimento do corpo docente, assim como sua observância ao cumprimento de prazos; melhoria no desenvolvimento e produção de material didático, de ferramentas de apoio ao acompanhamento e julgamento de desempenho; melhoria na elaboração e aplicação de provas, no tempo de resposta ao aluno, na comunicação e entrosamento profissional entre tutores presencias e a distância; redução dos conflitos internos e do desgaste dos profissionais envolvidos.

\section{CONSIDERAÇÕES FINAIS}

Apesar das dificuldades encontradas na atividade pioneira de implantação da EaD no IF-SC e de que esta modalidade de educação encontra-se em processo de construção, maturação e é, até então, motivo de indagações e discordâncias, acredita-se que, mesmo com desgastes oriundos "do novo", o IF-SC vem construindo um marco na história da Instituição.

O aprendizado obtido através do CSTGP já está gerando frutos que não mais precisam partir do nada. A perspectiva inicial, concretizada através de seis polos em 2007, outros quatro em 2008 e mais três em 2009, agora é ampliada não mais como perspectiva, mas como implementação de fato, para mais 25 polos neste ano de 2010. Os alunos do EaD, que representavam $13 \%$ do total de discentes da unidade de Florianópolis em 2009, representarão em 2010 cerca de 50\% do total.

Por outro lado, e refletindo o exposto por Ribas (2009), deficiências observadas no caminhar do processo de implantação do curso, não podem ser esquecidas, sob pena de comprometimento do processo ensino e aprendizagem e até mesmo da instituição como um todo. São elas:

a) Ausência de indicações, tanto no Plano de Desenvolvimento Institucional (PDI) como no Plano Pedagógico Institucional (PPI), de referências para condução de ações e ofertas de cursos na modalidade a distância;

b) Carência de instrumentos para avaliação de curso, na modalidade a distância, instruídos pela Comissão Própria de Avaliação - CPA;

c) Inexistência de um sistema de controle acadêmico parametrizado;

d) Carência de infraestrutura física, organizacional, tecnológica e de recursos humanos capaz de atender as necessidades de um programa regular em $\mathrm{EaD}$;

e) Falta de reconhecimento e validação das atividades dos coordenadores e professores participantes do processo junto à equipe dirigente do IF-SC;

f) Ausência da adoção de planilha orçamentária e distribuição de recursos;

g) Inexistência de programas para capacitação de pessoas em EaD;

h) Pequena capilaridade da EaD nos diversos departamentos de ensino.

Moore e Kearsley (2008, p.202) afirmam: “Antes de ir adiante e investir em um programa de educação a distância, os dirigentes de uma instituição precisam considerar inicialmente se tal iniciativa é realmente apropriada para cumprir sua missão.” 
Também, Colombo (2004) manifesta-se quanto ao aprendizado da gestão educacional, afirmando que, ao melhorar os processos ou inovar a sistemática de se fazer bem feito, os gestores levarão a instituição a patamares de excelência, permitindo, com isso, conduzi-la à liderança de mercado. Cabe, neste momento, ressaltar que, para uma instituição pública, a expressão liderança de mercado pode ser entendida como: eficácia no desempenho de sua função social - educação pública e gratuita para todos.

Com a perspectiva desafiante que se apresenta para o futuro, é imperiosa tal reflexão como ponto de partida para adoção de uma política institucional sólida em $\mathrm{EaD}$, de forma a eliminar ou reduzir substancialmente as carências sumarizadas anteriormente. Como as bases da teoria de planejamento indicam, mesmo com a existência de um modelo inicial adotado, é crucial a análise e reconstrução da infraestrutura de suporte às atividades pedagógicas e administrativas do programa UAB e um redesenho do modelo de gestão para a EaD no âmbito do Instituto Federal de Santa Catarina - IF-SC.

\section{REFERÊNCIAS BIBLIOGRÁFICAS}

CASTRO, C. M. Os dinossauros e as gazelas do ensino superior. In: MEYER JR, Victor (Org.). Dinossauros, gazelas e tigres: novas abordagens da administração universitária. Florianópolis: Insular, 2002.

COLOMBO, S. S. Gestão Educacional: uma nova visão. Porto Alegre: Artmed, 2004

MAIA, C; MATTAR, J. ABC da EaD: a educação a distância hoje. São Paulo: Pearson, 2007.

MAIA, M. C. O uso da tecnologia de informação para a educação a distância no ensino superior. 2003. Tese (Doutorado em Administração de Empresas) - Escola de Administração de Empresas de São Paulo da Fundação Getúlio Vargas, São Paulo, 2003.

MOORE, M. G.; KEARSLEY, G. Educação a Distância: uma visão integrada. São Paulo: Cengage Learning, 2008.

OLIVEIRA, D. P. R. Planejamento estratégico. São Paulo: Atlas, 2007.

PIMENTEL, N. M. Educação a distância. Florianópolis: SEaD/UFSC, 2006.

RIBAS, J. C. C; HERMENEGILDO, J. L. S. A Educação a distância no IF-SC: trajetória e a necessidade de uma política institucional. In: $15^{\circ}$ Congresso Internacional ABED de EaD, 2009. Fortaleza: ABED, 2009.

SCHNEIDER, Maria Clara Kaschny. Educação a distância: desafios para a interação na sala de aula virtual pautados na transposição da tecnologia nos projetos de videoconferência. 1999. Dissertação (Mestrado em Engenharia de Produção) Programa de Pós-Graduação em Engenharia de Produção. Universidade Federal de Santa Catarina, Florianópolis, 1999.

VERDUIN, J. R; CLARK, T. Distance education: the foundations of effective practice. San Francisco: Oxford, 1991. 